\title{
Distribution of lipids and fatty acids in corals by their taxonomic position and presence of zooxanthellae
}

\author{
Andrey B. Imbs*, Nikolay A. Latyshev, Tatyana N. Dautova, Yurii Y. Latypov \\ A.V. Zhirmunsky Institute of Marine Biology, Far-Eastern Branch of the Russian Academy of Sciences, 17 Palchevskogo Str., \\ 690041 Vladivostok, Russian Federation
}

\begin{abstract}
The lipid class and fatty acid (FA) composition for 93 species of reef-building and soft corals from the South China Sea (Vietnam) were analyzed and statistically compared to study systematic patterns of the distribution of lipids in corals and the influence of zooxanthellae on the lipids of symbiont-host association. The lipid and FA compositions of hexacorals and octocorals significantly correlated with their taxonomic position, but the lipid features of species within each of these systematic groups mainly depended on the presence of zooxanthellae. The hexacorals had lower content of polar lipids (PL), sterols (ST), and monoalkyldiacylglycerols (MADAG), but higher content of triacylglycerols (TG) and wax esters (WE) than the octocorals. On average, zooxanthellate species contained less structural lipids (PL+ST), but more MADAG when compared to azooxanthellate species. Tetracosapolyenoic acids 24:5n-6 and 24:6n-3 were chemotaxonomic markers for octocorals, whereas 22:5n-6 was a marker for Milleporidae. A strong correlation was apparent between zooxanthellate coral family and/or genus and the content of the unsaturated FA; 12 FAs were significant for the separation of azooxanthellate and zooxanthellate specimens. The latter had lower concentrations of 7-Me-16:1n-10, 18:1n-7, and six $C_{20-24}$ polyunsaturated FA, but higher concentrations of 16:0, 16:2n-7, 18:3n-6, and $18: 4 n-3$. The presence of $>2 \%$ of $18: 3 n-6$ and $18: 4 n-3$ of total FA is characteristic of zooxanthellate corals. An inverse correlation was established between the content of 18:3n-6 and 16:2n-7 in zooxanthellate soft corals. The present study highlights the importance of zooxanthellae in coral lipid metabolism, especially when compared with symbiont-host exchanges in reef-building and soft corals.
\end{abstract}

KEY WORDS: Lipid classes · Fatty acids · Hexacorallia - Octocorallia $\cdot$ Zooxanthellae $\cdot$ Biomarkers · Chemotaxonomy $\cdot$ Coral reef ecology

Resale or republication not permitted without written consent of the publisher

\section{INTRODUCTION}

Lipids form up to $40 \%$ of coral dry biomass (Stimson 1987, Harland et al. 1993, Ben-David-Zaslow \& Benayahu 1999, Yamashiro et al. 1999). In healthy corals, triacylglycerol (TG) and wax esters (WE) are the main storage lipids, accounting for 40 to $73 \%$ of total lipids, with sterols (ST) and polar lipids (PL), the main structural lipids, making up 9 to $60 \%$ of total lipids (Harland et al. 1993, Yamashiro et al. 1999, 2005, Grottoli et al. 2004). The majority of PL (>80\%) is composed of widespread phospholipids (phosphatidylcholine, phosphatidylethanolamine, and phosphatidylserine), and less common phosphonolipids (Joseph 1979, Lam et al. 1981, Latyshev et al. 1986, Imbs et al. 2006).

Lipids are involved in a majority of biochemical and physiological processes in corals; therefore, changes in the lipid composition reflect changes in the ecology, nutrition, and health of these animals. The structural lipids (ST and PL) typically remain stable with shortterm changes in nutrient state (Meyers 1979), though both have been found to fluctuate with bleaching (Grottoli et al. 2004). The proportion of storage lipids decreased, resulting in a proportionate increase in some structural lipids in coral species after a bleaching event (Grottoli et al. 2004, Yamashiro et al. 2005, 
Bachok et al. 2006, Rodrigues et al. 2008). The composition of lipids depends on the light regimes (Meyers 1979, Saunders et al. 2005). Turbinaria reniformis maintained in high-light conditions had higher concentrations of fatty acid (FA) and ST than the shaded corals (Treignier et al. 2008). Lipid content in corals varies during the annual cycle. PL in healthy Goniastrea aspera were highest in the winter, while TG and WE were highest in the summer (Oku et al. 2003). These seasonal variations are probably connected with changes in metabolic rate due to variations in sea surface temperature. Tumor coral tissue is characterized by a reduced level of storage lipids (Yamashiro et al. 2001) that may indicate the heterotrophic mode of tumors nutrition or energy withdrawal by tumor from the surrounding normal tissues.

FA are the main constituents of lipids. In a healthy symbiotic association, corals obtain their FA endogenously, mainly from the photosynthetic fixation of carbon by zooxanthellae (endosymbiotic dinoflagellates of the Symbiodinium group) (Patton \& Burris 1983, Patton et al. 1983, Harland et al. 1993) and from host cell de novo synthesis using glucose derived from zooxanthellae as a major source of carbon (Oku et al. 2003). FA synthesis occurs in parallel both in zooxanthellae and in the host (Oku et al. 2003). All corals derive their FA via heterotrophic feeding on phytoand zooplankton and dissolved organic matter, in addition to endogenous synthesis (Sorokin 1993, Ayukai 1995, Fabricius \& Dommisse 2000). FAs are most probably indicative of external food sources (Dalsgaard et al. 2003). In addition, zooxanthellae have an FA composition different from that of external food sources (Bishop \& Kenrick 1980, Zhukova \& Titlyanov 2003), The transport of FA from zooxanthellae to the host has been documented (Harland et al. 1993, Al Moghrabi et al. 1995, Ward 1995, Papina et al. 2003). Therefore, the absence of symbiotic dinoflagellates in corals should lead to a significant difference in lipid and FA compositions between zooxanthellate and azooxanthellate coral species (Imbs et al. 2007b).

FA composition is often specific to different groups of organisms (Volkman 1999). After the first attempt of wide screening of reef-building corals (Meyers 1977), several reliable comparisons of FA compositions of scleractinians and soft coral have been performed (Latyshev et al. 1991, Carballeira et al. 2002, Imbs et al. $2007 a, b)$. The first modern simultaneous investigation of lipid class and FA composition of Okinawa cnidarians was made by Yamashiro et al. (1999). Recently, we have shown that several FA sets are useful for the chemotaxonomic studies of reef building and soft corals (Imbs et al. 2007a, Imbs \& Dautova 2008). Unfortunately, most studies of FA composition in corals have examined only a single reef-building species. Conse- quently, comparable data on the lipid composition of healthy corals are very limited (Joseph 1979, Harland et al. 1993, Yamashiro et al. 1999), and the features of lipid class content for coral taxonomic groups, as well as zooxanthellate and azooxanthellate coral groups, remain unclear (Pham et al. 2008). In addition, the high variability among the data published on FA and lipid compositions strongly limits the capacity to make sound generalization about taxonomic trends. Several possibilities have been proposed to explain the high variability of these data: (1) different collection locations and environment conditions, i.e. water temperature, collection depth, light regime, season; (2) speciesspecific traits; (3) unnoticed partial bleaching; (4) specimen number limitation; and (5) different approaches to lipid extraction and analysis.

To improve the situation, we used the same lipid analysis technique for the screening of more than 100 coral specimens collected in the shallow waters of Vietnam on one occasion. Lipid class and FA composition of total lipids of hexacoral and octocoral species were examined to determine: (1) distribution of the lipid classes and FA in different taxonomic coral groups; (2) significant differences in the lipid class and FA compositions between zooxanthellate and azooxanthellate species.

\section{MATERIALS AND METHODS}

A total of 51 specimens of reef-building hexacorals (stony corals) belonging to 21 genera (10 families) and 58 specimens of octocorals (soft corals) including 39 alcyonarians and 19 gorgonians (21 genera, 12 families) were collected (Table S1 available in the supplement at www.int-res.com/articles/suppl/m409p065_ supp.pdf). The unique octocoral Heliopora coerulea, which has a rigid aragonitic skeleton similar to stony hexacorals, was also studied. Among the corals collected, 2 genera of stony corals (Balanophyllia and Tubastrea), 1 genus of alcyonarians (Dendronephthya), 6 genera of gorgonians (Annella, Melithaea, Parisis, Menella, Paracis, and Viminella), and Siphonogorgia were azooxanthellate; other genera contained zooxanthellae (Fabricius \& Alderslade 2001, van Oppen et al. 2005).

Coral were collected by SCUBA at 3 to $18 \mathrm{~m}$ depths (5 specimens at 90 to $300 \mathrm{~m}$ by drag) in the South China Sea (Vietnam) in May 2007 (Table S1). Stony corals were identified by the use of the taxonomic scheme of Wells (1956). Soft coral species identification was carried out under light microscope (200 to $400 \times$ magnification) using the arrangement of sclerites. Colonies were carefully cleaned of all noncoral debris. Collected samples were placed immediately into tanks 
under water at the site of collection and transported to the laboratory within $0.5 \mathrm{~h}$. Three different parts of a colony from each specimen were used for lipid analysis.

The coral samples were crushed into 1 to $3 \mathrm{~mm}$ pieces, and total lipids were extracted by intensive homogenization in a chloroform:methanol $(1: 2 \mathrm{v} / \mathrm{v})$ mixture (30 $\mathrm{ml}$ for $10 \mathrm{~g}$ of coral wet wt). The obtained homogenate was filtered, and the residue was repeatedly extracted $\left(6 \mathrm{~h}, 4^{\circ} \mathrm{C}\right)$ in a chloroform:methanol $(2: 1$ $\mathrm{v} / \mathrm{v})$ mixture $(2 \times 30 \mathrm{ml})$. The extracts were then mixed and separated into layers by adding $35 \mathrm{ml}$ of water and $30 \mathrm{ml}$ of chloroform. The lower layer was evaporated, and the total lipids obtained were redissolved in chloroform and stored at $-18^{\circ} \mathrm{C}$.

Lipid classes were separated by 1-dimensional silica gel thin-layer chromatography (TLC). The precoated Merck Kieselgel $60 \mathrm{G}$ plates $(10 \mathrm{~cm} \times 10 \mathrm{~cm})$ were first developed to their full length with $n$-hexane: diethyl ether:acetic acid (70:30:1 by vol.) and finally to $25 \%$ length with chloroform:methanol:benzene: $28 \%$ $\mathrm{NH}_{4} \mathrm{OH}$ (65:30:10:6 by vol.). After drying in a stream of air, plates were sprayed with $10 \% \mathrm{H}_{2} \mathrm{SO}_{4} / \mathrm{MeOH}$ and heated at $180^{\circ} \mathrm{C}$ for $10 \mathrm{~min}$. The chromatograms were scanned by an image scanner (Epson Perfection 2400 PHOTO) in a grayscale mode. Percentages of lipid contents were based on band intensity using an image analysis program (Sorbfil TLC Videodensitometer). Units were calibrated using known standards for each lipid class.

Fatty acid methyl esters (FAME) were obtained by a sequential treatment of the total lipids with $1 \%$ sodium methylate/methanol and $5 \% \mathrm{HCl} /$ methanol according to Carreau \& Dubacq (1979) and purified by preparative TLC, using the precoated silica gel plates Sorbfil PTLC-AF-V developed in benzene. $N$-acylpyrrolidide derivatives of FA were prepared according to Andersson (1978).

A gas chromatography (GC) analysis of FAME was carried out on a Shimadzu GC-17A chromatograph with a flame ionization detector. A SUPELCOWAX 10 (Supelco) capillary column $(30 \mathrm{~m} \times 0.25 \mathrm{~mm}$ inner diameter) was used at $205^{\circ} \mathrm{C}$. The injector and detector temperatures were $240^{\circ} \mathrm{C}$. Helium was used as the carrier gas at a linear velocity of $30 \mathrm{~cm} \mathrm{~s}^{-1}$. FAME were identified by comparison with authentic standards (a mixture of polyunsaturated FA (PUFA) methyl esters no. 3 from menhaden oil, Supelco) and with the use of a table of equivalent chain-lengths (ECL) (Christie 1988). The structures of FA were confirmed by gas chromatography-mass spectrometry (GC-MS) of their methyl esters and $N$-acylpyrrolidide derivatives with a Shimadzu GCMS-QP5050A instrument (electron impact at $70 \mathrm{eV}$ ) (Imbs et al. 2009).

Significant differences $(p<0.05)$ in lipid class or FA concentrations between coral species and groups were tested using a 1-way ANOVA. To represent relationships among the coral groups, all variables (square root of FA or lipid class contents) measured were included in principal components analyses (PCA). The analyses were performed using STATISTICA 5.1 (StatSoft).

\section{RESULTS}

\section{Distribution of lipid classes}

The distribution of main lipid classes such as WE, TG, ST, PL, free fatty acids (FFA), and less common monoalkyldiacylglycerols (MADAG) are shown in Table S2 in the supplement at www.int-res.com/ articles/suppl/m409p065_supp.pdf. In all cases, the amount of FFA did not exceed $3 \%$. All lipid classes (except for FFA) were used as variables for PCA. Stony and soft corals were clearly separated into 2 regions (dividing line $\mathrm{A}-\mathrm{A}$ ) of the 2-dimensional space formed by Axis 1 and Axis 2 (Fig. 1). Both axes together explained $77 \%$ of the total data variance (Axis 1:58\%). The particular separation of zooxanthellate and azooxanthellate coral specimens was also observed (dividing line $\mathrm{B}-\mathrm{B}$ ). Curved lines were manually drawn to determine the boundaries of the regions for 6 coral groups: azooxanthellate and zooxanthellate alcyonarians, gorgonians, and stony corals. As Fig. 1 indicates, the azooxanthellate species fall out of the regions of zooxanthellate species for all 3 taxonomic groups mentioned above. The separation of stony and soft corals as well as reef-building and azooxanthellate stony corals was generated in axis 1 . Axis 2 served mainly as a discriminant between 4 groups of the soft corals. Axis 1 was influenced by all lipid classes; Axis 2 was mainly defined by MADAG followed by ST and PL (Table 1).

A pairwise comparison of lipid class composition of the coral groups segregated during PCA (Fig. 1) was performed. Fig. 2 presents the content (mean \pm SD) of PL, ST, TG, MADAG, and WE in these groups. The results of 1-way ANOVA tests ( $F$ ratio, p) of lipid class concentrations between pairs of the coral groups were combined in Table 2.

The content of PL $(28.8 \pm 4.8 \%)$ and ST $(11.7 \pm 1.5 \%)$ was 1.9 and $2.1 \times$ higher $(\mathrm{p}<0.01)$, respectively, and the content of TG $(9.7 \pm 1.0 \%)$ was $2.5 \times$ lower $(p<$ $0.05)$ in the azooxanthellate stony corals than that of PL $(15.5 \pm 5.3 \%)$, ST $(5.5 \pm 1.6 \%)$, and TG $(23.9 \pm 8.3 \%)$ in the stony corals with zooxanthellae. The difference in MADAG and WE content for these 2 stony coral groups was not significant (Table 2).

On average, the sum of PL $(16.1 \pm 5.9 \%)$, ST $(5.7 \pm$ $2.0 \%)$, and MADAG $(5.1 \pm 3.9 \%)$ in all the stony corals was $2.1 \times$ lower $(p<0.01)$ than that of PL $(32.1 \pm$ 


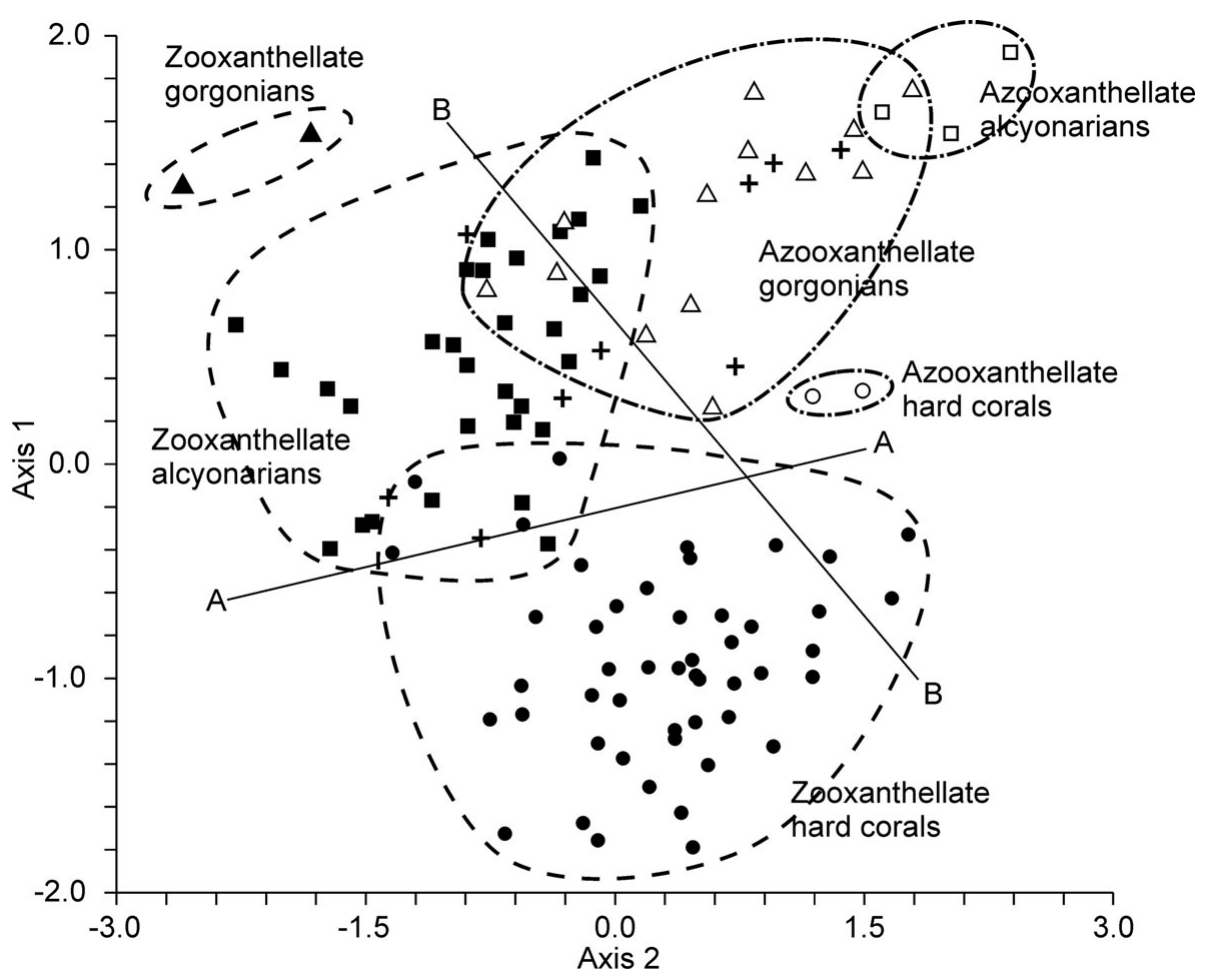

Fig. 1. Principal component analysis performed using the 5 variables (square root of lipid classes content) measured in all 110 coral specimens. Curved lines were arbitrarily drawn to delimit regions for each group. - Zooxanthellate hexacorals, - zooxanthellate alcyonarians, A zooxanthellate gorgonians, O azooxanthellate hexacorals, $\square$ azooxanthellate alcyonarians, $\Delta$ azooxanthellate gorgonians, + no data for zooxanthellae

$10.3 \%)$, ST $(9.3 \pm 4.2 \%)$, and MADAG $(16.1 \pm 8.8 \%)$ in all the soft corals studied. In contrast, the sum of nonpolar lipids TG $(47.1 \pm 11.0 \%)$ and WE $(29.7 \pm 11.4 \%)$ in all the stony corals was $2.4 \times$ higher $(\mathrm{p}<0.01)$ than that of TG $(23.4 \pm 8.6 \%)$ and WE $(9.1 \pm 4.9 \%)$ in all the soft corals studied (Fig. 2, Table 2).

Four soft coral groups selected (cf. Fig. 1) did not differ in TG level ( $p>0.05)$ (Fig. 2, Table 2). All soft corals with zooxanthellae and all azooxanthellate soft corals were distinguished by content of PL, ST, MADAG ( $\mathrm{p}<$ $0.01)$, and WE $(\mathrm{p}<0.05)$. The latter coral group contained more PL and ST, but less MADAG and WE (Fig. 2). On average, the sum of PL and ST in zooxanthellate alcyonarians (35.9\%) and gorgonians (32.9\%) was $1.5 \times$ lower than that in azooxanthellate alcyonarians $(56.1 \%)$ and gorgonians (51.5\%) (Fig. 2). At the same

Table 1. Loading factors for each variable of the principal components analysis shown in Fig. 1. PL: polar lipids; ST: sterols; TG: triacylglycerols; MADAG: monoalkyldiacyl glycerols; WE: wax esters

\begin{tabular}{|lrr|}
\hline \multirow{2}{*}{ Variable } & \multicolumn{2}{c|}{ Factor loading } \\
& Axis 1 & Axis 2 \\
\hline PL & 0.91 & 0.24 \\
ST & 0.81 & 0.42 \\
TG & -0.66 & 0.02 \\
MADAG & 0.53 & -0.84 \\
WE & -0.83 & 0.13 \\
\hline
\end{tabular}

time, the sum of MADAG and WE in zooxanthellate alcyonarians (52.3\%) and gorgonians (54.0\%) was higher than that in azooxanthellate alcyonarians $(24.0 \%$ ) and gorgonians (35.5\%) (Fig. 2). The difference between zooxanthellate alcyonarians and azooxanthellate gorgonians $(p<0.05)$ and between azooxanthellate alcyonarians and zooxanthellate gorgonians $(\mathrm{p}<$ 0.05) was significant for all lipid classes, except for TG (Table 2).

The alcyonarians with and without zooxanthellae were different in their content of WE, MADAG, ST, and PL $(\mathrm{p}<0.05)$. The gorgonians with and without zooxanthellate $(p<0.01)$ differed in their content of MADAG only, and the highest level of this unusual lipid class $(43.3 \pm 12.2 \%)$ was found in Hicksonella gorgonians (Table S2).

Comparison of 2 zooxanthellate soft coral groups (alcyonarians and gorgonians) showed significant differences $(p<0.01)$ in the mean content of MADAG and WE only. Two azooxanthellate groups of these soft coral groups differed significantly $(\mathrm{p}<0.05)$ by PL, ST, and MADAG with lower value of $F$ ratio (2.2 to 4.2 ) (Table 2).

On the whole, taxonomic position determined the features of coral lipid composition on the subclass and order levels. On the order and family levels, the lipid composition depended above all on the presence of zooxanthellae. No significant difference in lipid composition was defined between genus and species within each family of corals. 

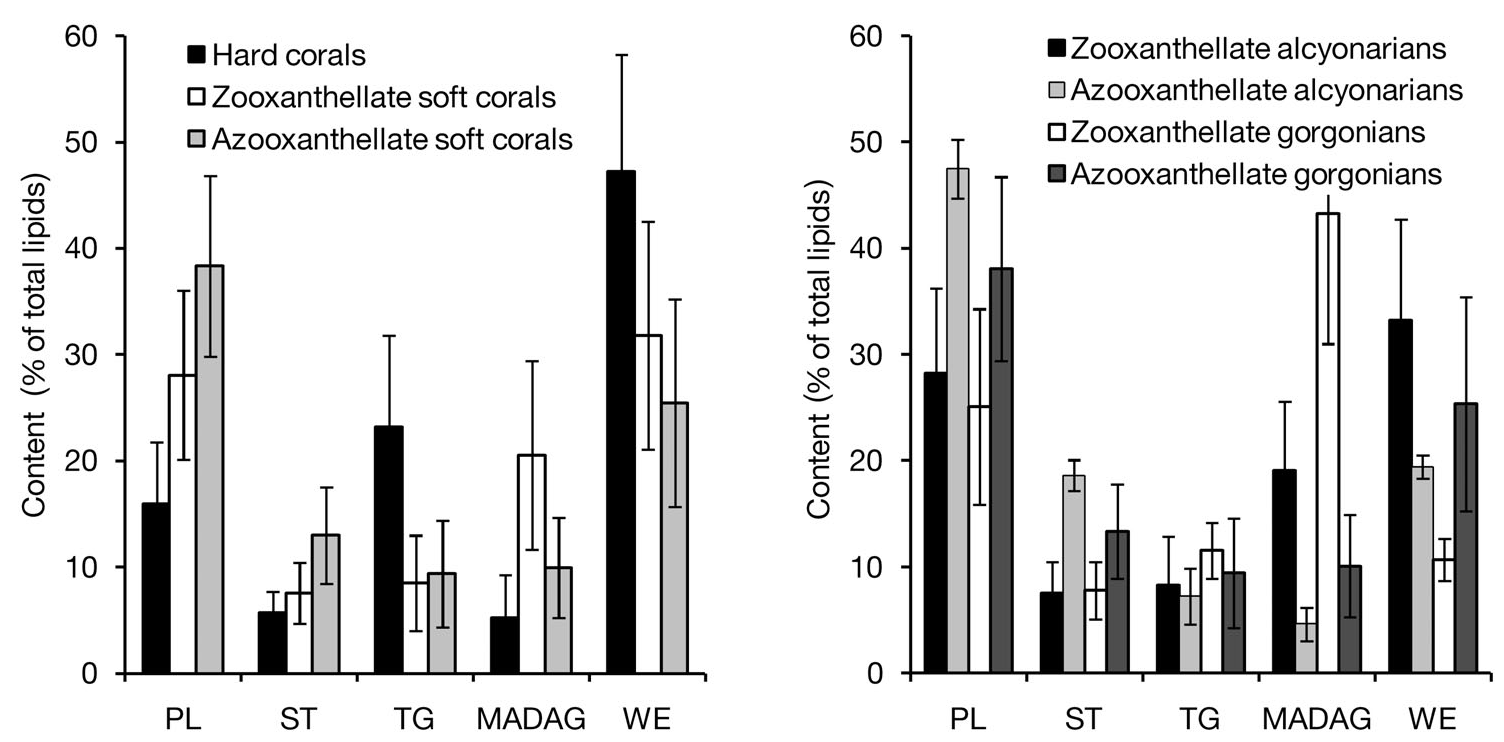

Fig. 2. Average contents $( \pm \mathrm{SD})$ of lipid classes (\% of total lipids) in different coral groups. See Table 1 for abbreviations

\section{Distribution of fatty acids}

Tables S3 \& S4 in the supplement show the distribution of FA of the total lipids in Hexacorallia (stony corals) and Octocorallia (soft corals) specimens studied. In hexacorals and octocorals, 25 and 40 main FA were determined, respectively. All octocorals contained a large portion of very-long-chain tetracosa- polyenoic FA (24:6n-3 and 24:5n-6), which were absent in all hexacorals.

\section{Hexacorals}

Relatively large numbers of the specimens studied belonged to 4 families (Acroporidae, Faviidae, Fungi-

Table 2. 1-way ANOVA paired comparison of the content of lipid classes between coral groups. See Table 1 for abbreviations

\begin{tabular}{|c|c|c|c|c|c|c|}
\hline Group pair & & PL & ST & TG & MADAG & WE \\
\hline Stony corals - soft corals & $\begin{array}{l}F \\
\mathrm{p}\end{array}$ & $\begin{array}{c}96.9 \\
<0.01\end{array}$ & $\begin{array}{c}31.6 \\
<0.01\end{array}$ & $\begin{array}{l}119.3 \\
<0.01\end{array}$ & $\begin{array}{c}68.0 \\
<0.01\end{array}$ & $\begin{array}{c}66.2 \\
<0.01\end{array}$ \\
\hline Zooxanthellate - azooxanthellate soft corals & $\begin{array}{l}F \\
\mathrm{p}\end{array}$ & $\begin{array}{c}18.5 \\
<0.01\end{array}$ & $\begin{array}{c}27.2 \\
<0.01\end{array}$ & $\begin{array}{c}0.4 \\
0.53\end{array}$ & $\begin{array}{c}22.0 \\
<0.01\end{array}$ & $\begin{array}{c}4.3 \\
0.04\end{array}$ \\
\hline Zooxanthellate - azooxanthellate stony corals & $\begin{array}{l}F \\
\mathrm{p}\end{array}$ & $\begin{array}{c}12.0 \\
<0.01\end{array}$ & $\begin{array}{c}28.1 \\
<0.01\end{array}$ & $\begin{array}{c}5.7 \\
0.02\end{array}$ & $\begin{array}{c}0.1 \\
0.76\end{array}$ & $\begin{array}{c}0.6 \\
0.45\end{array}$ \\
\hline Zooxanthellate stony corals - zooxanthellate alcyonarians & $\begin{array}{l}F \\
\mathrm{p}\end{array}$ & $\begin{array}{c}73.2 \\
<0.01\end{array}$ & $\begin{array}{c}16.9 \\
<0.01\end{array}$ & $\begin{array}{c}91.0 \\
<0.01\end{array}$ & $\begin{array}{l}140.8 \\
<0.01\end{array}$ & $\begin{array}{c}33.9 \\
<0.01\end{array}$ \\
\hline Zooxanthellate stony corals - azooxanthellate gorgonians & $\begin{array}{l}F \\
\mathrm{p}\end{array}$ & $\begin{array}{l}126.2 \\
<0.01\end{array}$ & $\begin{array}{c}90.0 \\
<0.01\end{array}$ & $\begin{array}{c}35.0 \\
<0.01\end{array}$ & $\begin{array}{c}24.3 \\
<0.01\end{array}$ & $\begin{array}{c}38.0 \\
<0.01\end{array}$ \\
\hline Zooxanthellate - azooxanthellate alcyonarians & $\begin{array}{l}F \\
\mathrm{P}\end{array}$ & $\begin{array}{c}16.7 \\
<0.01\end{array}$ & $\begin{array}{c}41.1 \\
<0.01\end{array}$ & $\begin{array}{c}0.2 \\
0.69\end{array}$ & $\begin{array}{c}14.2 \\
<0.01\end{array}$ & $\begin{array}{c}6.1 \\
0.02\end{array}$ \\
\hline Zooxanthellate alcyonarians - zooxanthellate gorgonians & $\begin{array}{l}F \\
\mathrm{p}\end{array}$ & $\begin{array}{c}0.3 \\
0.59\end{array}$ & $\begin{array}{c}0.0 \\
0.91\end{array}$ & $\begin{array}{c}1.0 \\
0.33\end{array}$ & $\begin{array}{c}23.9 \\
<0.01\end{array}$ & $\begin{array}{c}10.8 \\
<0.01\end{array}$ \\
\hline Zooxanthellate alcyonarians - azooxanthellate gorgonians & $\begin{array}{l}F \\
\mathrm{p}\end{array}$ & $\begin{aligned} & 9.0 \\
< & 0.01\end{aligned}$ & $\begin{array}{c}19.3 \\
<0.01\end{array}$ & $\begin{array}{c}1.0 \\
0.32\end{array}$ & $\begin{array}{c}16.5 \\
<0.01\end{array}$ & $\begin{array}{c}4.2 \\
0.05\end{array}$ \\
\hline Azooxanthellate alcyonarians - zooxanthellate gorgonians & $\begin{array}{l}F \\
\mathrm{p}\end{array}$ & $\begin{array}{l}18.1 \\
0.02\end{array}$ & $\begin{array}{l}36.9 \\
0.01\end{array}$ & $\begin{array}{c}3.2 \\
0.17\end{array}$ & $\begin{array}{l}34.7 \\
0.01\end{array}$ & $\begin{array}{l}44.2 \\
0.01\end{array}$ \\
\hline Azooxanthellate alcyonarians - azooxanthellate gorgonians & $\begin{array}{l}F \\
\mathrm{p}\end{array}$ & $\begin{array}{c}5.6 \\
0.03\end{array}$ & $\begin{array}{c}7.1 \\
0.02\end{array}$ & $\begin{array}{c}0.6 \\
0.44\end{array}$ & $\begin{array}{c}6.2 \\
0.03\end{array}$ & $\begin{array}{c}1.3 \\
0.27\end{array}$ \\
\hline Zooxanthellate gorgonians - azooxanthellate gorgonians & $\begin{array}{l}F \\
\mathrm{p}\end{array}$ & $\begin{array}{c}3.1 \\
0.10\end{array}$ & $\begin{array}{c}2.2 \\
0.16\end{array}$ & $\begin{array}{c}0.2 \\
0.69\end{array}$ & $\begin{array}{c}61.5 \\
<0.01\end{array}$ & $\begin{array}{c}4.2 \\
0.06\end{array}$ \\
\hline
\end{tabular}


idae, and Poritidae), which seemed to be suitable for the examination of a relationship between FA composition and taxonomic position of these animals. Recently, the set of 10 PUFA was successfully used as PCA variables for chemotaxonomic investigations of reef-building corals (Imbs et al. 2007a). ANOVA tests for each possible pair from the 4 families indicated that there were no differences ( $p>0.05$ ) in 20:4n-6, 18:3n6 , and 18:4n-3, but most of the pairs differed in $\mathrm{C}_{18-20}$ monoenoic FA. Furthermore, these coral families lacked 22:5n-6. Therefore, the initial set of PUFA was corrected, and 9 variables $(18: 1 n-9,18: 1 n-7,20: 1 n-9$, 20:1n-7, 20:4n-3, 20:5n-3, 22:4n-6, 22:5n-3, and 22:6n-3) were used for PCA. The outcome of the analysis is shown in Fig. 3. The first 2 components explained $59.8 \%$ of the total data variance. The 4 families of corals can be recognized in the score plot. Additionally, the family Poritidae subdivided into 2 genera, Porites and Goniopora. Based on the FA loadings along the 2 axes (Table 3), the separation of Faviidae and

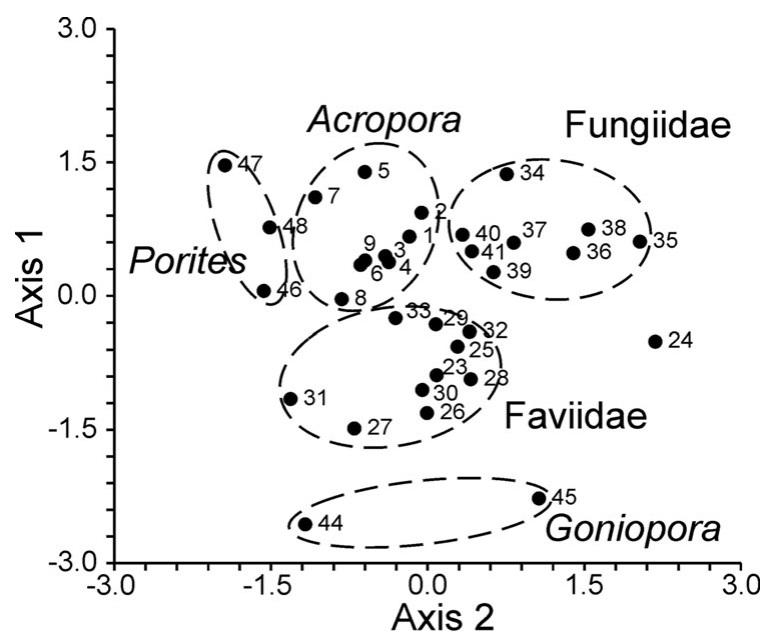

Fig. 3. Principal component analysis performed using 11 variables (square root of selected unsaturated fatty acid content) measured in 4 representative stony coral families. See Table S1 for specimen numbering. Curved lines were arbitrarily drawn to delimit regions for each group

Table 3. Loading factors for each variable of the PCA shown in Fig. 3

\begin{tabular}{|lrr|}
\hline \multirow{2}{*}{ Variable } & \multicolumn{2}{c|}{ Factor loading } \\
& Axis 1 & Axis 2 \\
\hline $18: 1 \mathrm{n}-9$ & 0.18 & -0.75 \\
$18: 1 \mathrm{n}-7$ & -0.82 & 0.19 \\
$20: 1 \mathrm{n}-9$ & -0.13 & -0.80 \\
$20: 1 \mathrm{n}-7$ & -0.91 & -0.04 \\
$20: 4 \mathrm{n}-3$ & -0.67 & -0.51 \\
$20: 5 \mathrm{n}-3$ & 0.23 & -0.67 \\
$22: 4 \mathrm{n}-6$ & 0.58 & -0.37 \\
$22: 5 \mathrm{n}-3$ & 0.57 & -0.16 \\
$22: 6 \mathrm{n}-3$ & -0.48 & -0.56 \\
\hline
\end{tabular}

Goniopora from Porites, Acropora, and Fungiidae was mainly due to differences in the levels of 20:1n-9, 18:1n-7, 20:4n-3, and $C_{22}$ PUFA (Axis 1). The separation of Porites, Acropora, and Fungiidae was mainly due to differences in the levels of $18: 1 n-9$ and 20:1n-9, followed by 20:4n-3, 20:5n-3, and 22:6n-3 (Axis 2).

The acid 22:5n-6 was detected in the scleractinian corals in a trace amount only (about $0.1 \%$ of total FA). In comparison with Scleractinia, hydrocorals of the genus Millepora were characterized by the presence of $22: 5 n-6 \quad(7.1 \%)$; high levels of $18: 0$ (15.4\%), 20:0 $(4.4 \%), 22: 6 \mathrm{n}-3(32.7 \%)$; and very low levels of 18:3n-6 and 20:4n-6 (Table S3). Total FA of Galaxea fascicularis, the single species studied from the family Oculinidae, contained $1.4 \%$ of $22: 4 n-3$. The high concentration of $18: 1 \mathrm{n}-9$ (up to $21.5 \%$ of total FA) was characteristic of the genus Porites. Two azooxanthellate scleractinians, Balanophyllia sp. and Tubastrea aurea, were distinguished from zooxanthellate scleractinians by a high content of 18:1n-9, 7-Me-16:1n-10, $20: 5 n-3$, and $22: 5 n-3$ and low content of $18: 3 n-6$ and $18: 4 n-3$. The sum of the last 2 FAs $(1.5 \%)$ in azooxanthellate scleractinians was significantly lower $(p<0.01)$ than that $(10.3 \pm 3.5 \%)$ in zooxanthellate scleractinians.

\section{Octocorals}

For all soft coral specimens, PCA was performed on 45 FA variables summarized in Table S4. Azooxanthellate and zooxanthellate soft corals were clearly separated (Fig. 4). Only one Lobophytum specimen (Fig. 4, data point 61) fell into the azooxanthellate region. Zooxanthellate soft corals were subdivided into 2 groups. Alcyonarians of the genera Carijoa, Alcyonium, Cladiella, Lemnalia, Nephthea; gorgonians of the genus Hicksonella; and blue coral Heliopora coerulea fell into the first group and were characterized by low level of 16:2n-7. The second group was formed by alcyonarians of the genera Lobophytum and Sarcophyton with a high level of 16:2n-7. The Sinularia specimens distributed between these 2 coral groups differed in the level of $16: 2 n-7$. The high content of 16:2n-7 (up to $16.4 \%$ ) was accompanied by the low content of 18:3n-6 and vice versa in the zooxanthellate soft corals, except for the genus Nephthea.

Both axes together (Fig. 4) explained only 38.6\% of the total data variance (Axis 1: $26.6 \%$ ). The separation of the zooxanthellate and azooxanthellate species was generated in Axis 1. For each of the 45 FAs from Table S4, the contents in zooxanthellate specimens were compared to those in azooxanthellate coral specimens; the significant difference $(p<0.01)$ was indicated only for 12 FAs, namely 16:0, 16:2n-7, 7-Me-16:1n-10, 


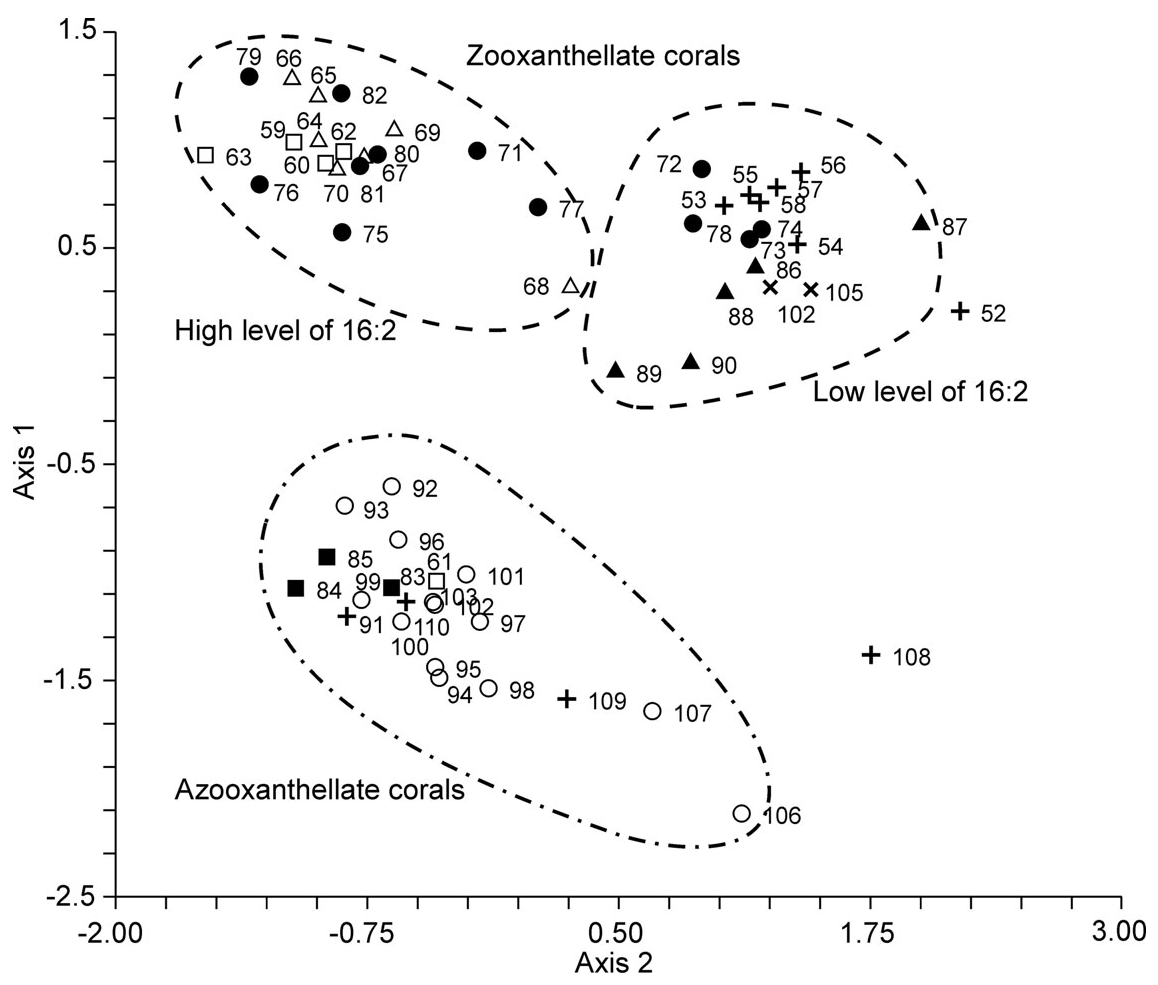

Fig. 4. Principal component analysis performed using 55 variables (square root of total fatty acid content) measured in all soft corals. See Table S1 for specimen numbering. Curved lines were arbitrarily drawn to delimit regions for each group. (•) Sinularia, (ם) Dendronephthya, (ム) Lemnalia and Nephthea, (O) azooxanthellate gorgonians, () Lobophytum, $(\Delta)$ Sarcophyton, (x) zooxanthelate gorgonians, (+) other species

18:1n-7, 18:3n-6, 18:4n-3, 20:4n-6, 22:4n-6, 22:5n-6, 22:5n-3，24:5n-6, and 24:6n-3. The same FAs had the highest loadings on Axis 1 (Table 4). Levels of 18:3n-6, 18:4n-3, 16:2n-7, and 16:0 were higher in zooxanthellate species. Levels of other significant FAs were higher in azooxanthellate species. Axis 2 served mainly to discriminate between 2 groups of the zooxanthellate corals. An ANOVA test of the contents of each FA between these 2 groups indicated significant differences $(\mathrm{p}<0.01)$ for $16: 1 \mathrm{n}-9, \quad 16: 2 \mathrm{n}-7, \quad 18: 2 \mathrm{n}-7, \quad 18: 2 \mathrm{n}-6$, 18:3n-6, 20:5n-3, and 22:6n-3. At the same time, $16: 2 n-7,16: 1 n-9$, and 18:2n-7 had the highest positive loadings, and 18:3n-6, 18:2n-6, 20:5n-3, and $22: 6 n-3$ had the highest negative loadings (Table 4) on Axis 2 in Fig. 4.

Among the soft coral genera studied, Lobophytum, Sarcophyton, and Sinularia were the most representative (making up about half of the specimens). The application of the full matrix of FA (Table S4) did not lead to a separation of these 3 genera (see Fig. 4). Therefore, PCA was performed on a set of 11 PUFA variables
Table 4 . Fatty acids (mean $\pm \mathrm{SD}, \%$ of total FA) that were significantly different ( $p \leq 0.01$ ) between azooxanthellate and zooxanthellate corals and between zooxanthellate corals with low and high levels of 16:2n-7: content (mean $\pm \mathrm{SD}, \%$ of total FA) and loading values on principal component analysis in Fig. 4

\begin{tabular}{|c|c|c|c|c|c|}
\hline \multirow[t]{2}{*}{ Fatty acid } & \multicolumn{2}{|c|}{ Content of fatty acid } & \multicolumn{2}{|c|}{$\begin{array}{c}\text { Statistical } \\
\text { comparison }\end{array}$} & \multirow{2}{*}{$\begin{array}{c}\text { PCA analysis } \\
\begin{array}{c}\text { Factor loading } \\
\text { for Axis } 1\end{array}\end{array}$} \\
\hline & $\begin{array}{l}\text { Zooxanthellate } \\
\text { corals }\end{array}$ & $\begin{array}{c}\text { Azooxanthellate } \\
\text { corals }\end{array}$ & $F$ & $\mathrm{p}$ & \\
\hline $16: 0$ & $26.9 \pm 8.5$ & $11.3 \pm 3.3$ & 40.0 & $<0.01$ & 0.76 \\
\hline $16: 2 n-7$ & $5.3 \pm 4.5$ & $0.6 \pm 0.4$ & 44.6 & $<0.01$ & 0.58 \\
\hline 7-Me-16:1n-10 & $1.4 \pm 2.1$ & $3.6 \pm 2.3$ & 7.3 & 0.01 & -0.61 \\
\hline $18: 1 n-7$ & $0.4 \pm 0.6$ & $2.0 \pm 0.6$ & 20.4 & $<0.01$ & -0.85 \\
\hline $18: 3 n-6$ & $3.8 \pm 4.5$ & $0.5 \pm 0.4$ & 8.7 & 0.01 & 0.32 \\
\hline $18: 4 n-3$ & $3.0 \pm 1.3$ & $0.7 \pm 0.4$ & 46.8 & $<0.01$ & 0.61 \\
\hline $20: 4 n-6$ & $16.1 \pm 5.4$ & $28.5 \pm 7.2$ & 46.4 & $<0.01$ & -0.51 \\
\hline $22: 4 n-6$ & $0.4 \pm 0.3$ & $2.1 \pm 2.7$ & 7.2 & 0.01 & -0.67 \\
\hline $22: 5 n-6$ & $0.3 \pm 0.2$ & $1.9 \pm 1.4$ & 69.9 & $<0.01$ & -0.81 \\
\hline $22: 5 n-3$ & $0.2 \pm 0.1$ & $0.7 \pm 0.5$ & 10.8 & $<0.01$ & -0.65 \\
\hline $24: 5 n-6$ & $4.8 \pm 1.7$ & $10.8 \pm 4.4$ & 16.9 & $<0.01$ & -0.34 \\
\hline \multirow[t]{3}{*}{$24: 6 n-3$} & $1.4 \pm 0.8$ & $3.6 \pm 1.8$ & 55.2 & $<0.01$ & -0.58 \\
\hline & \multicolumn{2}{|c|}{ Zooxanthellate corals } & & & \\
\hline & $\begin{array}{l}\text { with low } \\
\text { level 16:2 }\end{array}$ & $\begin{array}{l}\text { with high } \\
\text { level 16:2 }\end{array}$ & $F$ & $\mathrm{p}$ & $\begin{array}{l}\text { Factor loading } \\
\quad \text { for Axis } 2\end{array}$ \\
\hline $16: 1 n-9$ & $0.2 \pm 0.1$ & $0.7 \pm 0.5$ & 12.5 & $<0.01$ & -0.31 \\
\hline $16: 2 n-7$ & $0.4 \pm 0.4$ & $8.1 \pm 3.4$ & 92.7 & $<0.01$ & -0.61 \\
\hline $18: 2 n-7$ & $0.1 \pm 0.2$ & $2.1 \pm 1.6$ & 27.6 & $<0.01$ & -0.56 \\
\hline $18: 2 n-6$ & $1.8 \pm 0.9$ & $0.2 \pm 0.2$ & 50.8 & $<0.01$ & 0.68 \\
\hline $18: 3 n-6$ & $6.4 \pm 4.8$ & $0.5 \pm 0.8$ & 27.0 & $<0.01$ & 0.60 \\
\hline $20: 5 n-3$ & $6.1 \pm 5.8$ & $1.8 \pm 1.0$ & 9.7 & $<0.01$ & 0.67 \\
\hline $22: 6 n-3$ & $6.6 \pm 2.2$ & $2.6 \pm 1.2$ & 43.9 & $<0.01$ & 0.70 \\
\hline
\end{tabular}




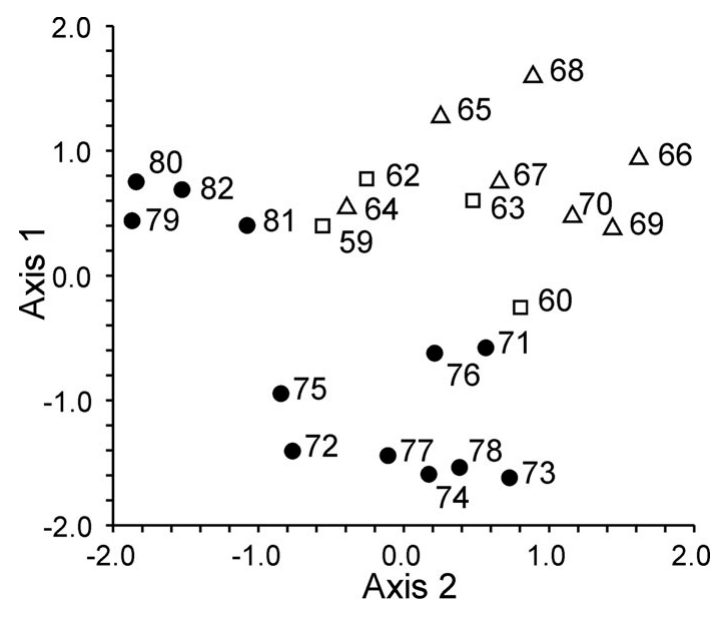

Fig. 5. Principal component analysis performed using 10 variables (square root of PUFA content) measured in 3 soft coral genera. Specimens are numbered as in Table S1. (•) Sinularia, () Lobophytum, $(\Delta)$ Sarcophyton

(18:3n-6, 18:4n-3，20:3n-6，20:4n-6，20:4n-3，20:5n-3, $22: 4 n-6,22: 5 n-6,22: 6 n-3,24: 5 n-6$, and 24:6n-3) that was previously applied for chemotaxonomy of octocorals (Imbs \& Dautova 2008). Fig. 5 shows the results of the PCA performed on PUFA data for the 23 specimens. Sinularia and Sarcophyton were clearly separated in the slightly overlapping regions of the 2dimensional space formed by Axis 1 and Axis 2. The Sinularia region could be conveniently divided into 2 groups. Lobophytum diffused into the kindred genus Sarcophyton. Both axes together explained $57.3 \%$ of the total data variance (Axis 1: $35.5 \%$ ). Pairwise comparison of FA data of the genera Lobophytum, Sarcophyton, and Sinularia showed the maximum difference in the level of 3 PUFA of $n-3$ series: 18:4n-3, 20:4n-3, and 24:6n-3.

\section{DISCUSSION}

\section{Distribution of lipid classes}

Corals were collected in the same season, region, and at relatively low depths to minimize variations of the lipid composition caused by these environmental conditions. However, corals are polytrophic organisms and we cannot disregard an influence of food sources on the coral lipids. Different food sources have a specific lipid composition (Dalsgaard et al. 2003). The wide variety of colonial forms and size of corallites (from $0.8 \mathrm{~mm}$ to $20 \mathrm{~cm}$ ) of the corals studied may influence access to external food sources, such as dissolved organic materials, detritus, phyto- and zooplankton, and may change the contribution of each source to total coral lipids.
Reef-building corals (Hexacorallia) did not form clusters in the PCA analysis, but were clearly separated from the soft corals (Octocorallia) based on their lipid class composition (Fig. 1). High levels of nonpolar lipids have been previously found in a number of hexacoral species (Yamashiro et al. 1999). The average content of the structural lipids in 2 azooxanthellate hexacoral species studied was higher than that in zooxanthellate hexacorals but nevertheless lower than in the octocorals. Thus, the predominance of the storage lipids $(70.5 \pm 8.5 \%$ of $\mathrm{TG}+\mathrm{WE})$ is a significant chemotaxonomic characteristic of reef-building corals, independent of the presence of zooxanthellae and variations of food sources.

This difference in lipid metabolism may be connected with the presence of a hard exoskeleton in reefbuilding corals. Lipids are the building blocks of cell membranes (mainly PL and ST) and a main long-term source of stored energy (mainly TG and WE) in corals. The exoskeleton keeps the shape of stony coral polyps, and therefore their cell membranes can have relatively high fluidity and require less structural lipids. Alternatively, skeleton formation in stony corals may be accompanied by high production of storage lipids. For example, the lipid class proportion in the octocoral Heliopora coerulea with a rigid skeleton was closer to that in the scleractinians (Table S2).

PCA results suggest that the presence of zooxanthellae, as well as their taxonomic identity, strongly influence the proportion of lipid classes in octocorals (Fig. 1). Based on lipid class composition, all octocoral specimens clustered into 2 conventional taxonomic groups (aclyonarians and gorgonians); each of these groups clustered according to the presence of zooxanthellae. Similar to hexacorals, the absence of zooxanthellae decreases the relative concentration of storage lipids (on average, twofold) in a healthy coral colony (Table S2). Decreases of relative content of storage lipids, accompanied by increases of structural lipid content during bleaching (the loss of zooxanthellae) of reef-building corals, have been demonstrated (Yamashiro et al. 2005). Thus, the zooxanthellae play an important role in the accumulation of storage lipids in corals. Among 2 storage lipids WE and TG, 4 octocoral groups differed significantly in the level of WE only (Table 2). WE are probably produced by the coral host, whereas TG level depends on casual variations of food sources.

Unusual MADAG have been previously found in corals (Joseph 1979, Yamashiro et al. 1999). MADAG have chemical bonds that are stable against hydrolytic enzymes such as lipases. We attribute MADAG to structural lipids and agree with Joseph (1979) that the MADAG may stabilize coral membranes, which are exposed to highly active hydrolytic enzymes. The aver- 
age content of MADAG in the soft corals studied was $3 \times$ higher than in hermatypic corals, and the zooxanthellate soft corals were distinguished by the increased level of MADAG (Fig. 2). MADAG concentrates in the host cell tissue and is practically absent in the zooxanthellae (Imbs et al. 2010). Thus, polyps of zooxanthellate species produce a great quantity of MADAG and need endosymbionts to retain the level of neutral lipids. We surmise that MADAG regulates the interaction between cell membranes of coral host and zooxanthellae.

\section{Distribution of fatty acids}

Several FAs can serve as unique chemical markers of some coral taxonomic groups. Our study confirmed that 2 tetracosapolyenoic acids (TPA) (24:5n-6 and 24:6n-6) are chemotaxonomic markers of the subclass Octocorallia (Svetashev \& Vysotsky 1998) irrespective of the presence of zooxanthellae. Contrary to octocorals, none of hexacorals can synthesize TPA from $\mathrm{C}_{22}$ PUFA, and its enzymes cannot insert a double bound at $\Delta 5$ position of $22: 4 n-6$. Stony hydrocorals of the genus Millepora can synthesize 22:5n-6 (Table S3) and may be a unique characteristic of Milleporidae. Possible activity of $\Delta 5$ desaturase in the Millepora may explain the low level of 18:3n-6 and 20:4n-6 (Table S3), which are biosynthetic precursors of 22:5n-6.

Unfortunately, the composition of total FA is unusable for biochemical classification of families or genera of zooxanthellate hexacorals. Multivariate analysis of the unsaturated FA selected has been recently applied for this classification (Imbs et al. 2007a). The correlation between unsaturated FA and taxonomic position of scleractinians was evident (Fig. 3). Our present (Fig. 3) and previous results (Imbs et al. 2007a) showed that at least 5 scleractinian families (Acroporidae, Faviidae, Fungiidae, Pocilloporidae, and Poritidae) had a distinct PUFA composition. In spite of lipid variations caused by food sources, coral species within of some scleractinian families, and even some genera, had similar metabolisms and accumulation of PUFA.

Multivariate analysis of 11 unsaturated FAs, which have been used in the previous study (Imbs et al. $2007 b)$, confirmed the distinction between PUFA profiles of 3 representative alcyonarian genera: Lobophytum, Sarcophyton, and Sinularia (Fig. 5). The main loading of variables $18: 4 n-3,20: 4 n-3$, and $24: 6 n-3$ in the clusterization of these zooxanthellae alcyonarians pointed to differences in the pathway of $n-3$ series PUFA $(18: 4 \mathrm{n}-3 \rightarrow 20: 4 \mathrm{n}-3 \rightarrow 20: 5 \mathrm{n}-3 \rightarrow 22: 5 \mathrm{n}-3 \rightarrow 24: 5 \mathrm{n}-3 \rightarrow$ $24: 6 n-3)$. The main sources of $n-3$ series PUFA are zooxanthellae, free-living dinoflagellates, and diatoms. Thus, zooxanthellae and microalgae obtained with food are important for the formation of PUFA profiles of alcyonarians and the closely-related genera mentioned above, use these lipid resources differently.

The shallow-water gorgonian corals were distinguished by the predominance of n-6 PUFA (first of all, 20:4n-6 and 24:5n-6) (Table S4). Only Viminella (nonbranched gorgonians) contained less 24:5n-6 and much more $22: 4 n-6(9.2 \%$ instead of $0.7 \%$ on average for other soft corals studied). The same unusual accumulation of $22: 4 n-6$ because of the inhibition of biosynthetic pathway $22: 4 n-6 \rightarrow 24: 4 n-6 \rightarrow 24: 5 n-6$ has been previously described for some gorgonians (Imbs et al. 2009). Among the gorgonians studied, the highest level of n-3 PUFA 24:6n-3 and 20:5n-3, as well as the practical absence of 24:5n-6, was detected in a deepsea sample of Narella sp. that may indicate the strong influence of habitat depth on n-3:n-6 PUFA ratio in gorgonians. As shown for the reef-building coral Stylophora pistillata, the depth affects n-3:n-6 ratio of FA of neutral lipids, but does not affect phospholipid FA (Latyshev et al. 1991). FA composition of neutral lipids of a consumer depends on its food FA. Hence, specific FA composition of food sources may be one of the reasons for the predominance of n-3 PUFA in the deep-sea gorgonian Narella sp.

The division of the alcyonarians and gorgonians according to their total FA composition has been previously demonstrated (Imbs \& Dautova 2008). We surmised that this division is primarily caused by the presence of zooxanthellae in the alcyonarians and their absence in the gorgonians.

In fact, zooxanthellate and azooxanthellate soft corals were divided according to their total FA (Fig. 4), but only 4 FA variables $(16: 0,16: 2 n-7,18: 3 n-$ 6 , and 18:4n-3) significantly differed in these groups and had higher average content in zooxanthellate specimens (Table 4). Predominance of 16:0, 18:3n-6, and 18:4n-3 in FA of hexacoral zooxanthellae have been previously reported (Al Moghrabi et al. 1995, Papina et al. 2003, Zhukova \& Titlyanov 2003, Treignier et al. 2008). The level of $18: 3 n-6$ and $18: 4 n-$ 3 was very low in azooxanthellate alcyonarians (Imbs et al. 2007b), gorgonians (Imbs et al. 2009), and hexacorals Balanophyllia sp., Tubastrea aurea (Table S3), T. coccinea, and T. micrantha (Latyshev et al. 1991). On the contrary, the level of these acids in zooxanthellate hexacorals ranged from 2 to $15 \%$ of total FA (Table S3; Latyshev et al. 1991, Imbs et al. 2007a). These $\mathrm{C}_{18}$ PUFA are the main FAs of glycolipids, which play a key role in thylakoid membranes of zooxanthellae of reef-building corals (Tchernov et al. 2004). In the hermatypic coral Pavona frondifera, the loss of zooxanthellae leads to a decrease in the content of $18: 3 n-6$ and $18: 4 n-3$ from 12.2 to $1.8 \%$ (Bachok et al. 2006). Thus, the presence of more than 
$2 \%$ of $18: 3 n-6$ and $18: 4 n-3$ in total FA can be regarded as the criterion of the presence of zooxanthellae in corals.

Another specific marker of dinoflagellates is $22: 6 n-3$ (Viso \& Marty 1993), but this marker was not significant ( $\mathrm{p}>0.05$ ) between zooxanthellate and azooxanthellate soft corals (Fig. 4). The comparison of FA composition of several soft coral genera has earlier shown that high intraspecific dispersion in the content of 22:6n-3 exceeded interspecific differences (Imbs et al. $2007 \mathrm{c}$ ). We suggest that the use of $22: 6 n-3$ as a chemotaxonomic marker for soft corals is limited.

The inverse correlation between the content of 18:3n-6 and 16:2n-7 in the zooxanthellate soft corals was established. Azooxanthellate soft corals lacked 16:2n-7 (Imbs et al. 2007b, 2009; Table S4). The difference in substratum specificity of $\Delta 6$ desaturase in zooxanthellae, which convert $18: 2 n-6$ to $18: 3 n-6$ or $16: 1 n-7$ to $16: 2 \mathrm{n}-7$, can be accepted as a possible explanation of this correlation. This phenomenon has no genusspecific character for Sinularia. It is obvious that PUFA conversion in zooxanthellate stony and soft corals has different pathways since scleractinians contain only a trace amount of 16:2n-7. Neither $16: 2 n-7$ nor 18:3n-6 was present in zooxanthellate Millepora (Table S3; Latyshev et al. 1991).

Numerous examinations of the interactions between corals and microbes have shown that there is a dynamic microbiota living on the surface and, possibly, within the tissue of corals. Odd-chain and methylbranched FA plus 18:1n-7 were regarded as biomarkers of bacteria (Kaneda 1991). The content of these common bacterial FAs was significantly higher $(\mathrm{p}<$ 0.05) in the azooxanthellate species studied indicating the presence of a diverse bacterial community. The absence of zooxanthellae also correlated with the increase of 7-Me-16:1n-10 content. Probably, 7-Me$16: 1 \mathrm{n}-10$ does not characterize the whole bacterial community, but can serve as a biomarker of some specific bacterial groups associated with corals (Imbs et al. 2007 b).

In summary, a comprehensive database on the lipid composition of healthy reef-building and soft corals is presented. The lipid class and FA compositions of coral species significantly correlated with coral subclass, either Hexacorallia or Octocorallia. However, the lipid composition of species within these subclasses was mainly driven by the presence of zooxanthellae. The PUFA profile should be regarded as a fingerprint of families or some genera of zooxanthellate corals. The data obtained may serve as an important baseline for the investigation of transport and metabolism of lipids in healthy corals, as well as for the study of the changes in lipid composition caused by environmental factors, including coral bleaching.
Acknowledgements. This research was funded by the Russian Foundation of Basic Research (09-04-01040, 09-04-90304, and 09-04-98542).

\section{LITERATURE CITED}

Al Moghrabi S, Allemand D, Couret JM, Jaubert J (1995) Fatty acids of the scleractinian coral Galaxea fascicularis —effect of light and feeding. J Comp Physiol B 165: 183-192

Andersson BA (1978) Mass spectrometry of fatty acid pyrrolidides. Prog Chem Fats Other Lipids 16:279-308

> Ayukai T (1995) Retention of phytoplankton and planktonic microbes on coral reefs within the Great Barrier Reef, Australia. Coral Reefs 14:141-147

Bachok Z, Mfilinge P, Tsuchiya M (2006) Characterization of fatty acid composition of healthy and bleached corals from Okinawa, Japan. Coral Reefs 25:545-554

> Ben-David-Zaslow R, Benayahu Y (1999) Temporal variation in lipid, protein and carbohydrate content in the Red Sea soft coral Heteroxenia fuscescens. J Mar Biol Assoc UK 79:1001-1006

Bishop DG, Kenrick JR (1980) Fatty acid composition of symbiotic zooxanthellae in relation to their hosts. Lipids 15 : 799-804

Carballeira NM, Miranda C, Rodriguez AD (2002) Phospholipid fatty acid composition of Gorgonia mariae and Gorgonia ventalina. Comp Biochem Physiol B 131:83-87

Carreau JP, Dubacq JP (1978) Adaptation of macro-scale method to the micro-scale for fatty acid methyl transesterification of biological lipid extracts. J Chromatogr A 151: 384-390

Christie WW (1988) Equivalent chain lengths of methyl ester derivatives of fatty acids on gas chromatography-a reappraisal. J Chromatogr A 447:305-314

> Dalsgaard J, John MS, Kattner G, Muller-Navarra D, Hagen W (2003) Fatty acid trophic markers in the pelagic marine environment. Adv Mar Biol 46:225-340

Fabricius C, Alderslade P (2001) Soft corals and sea fans: a comprehensive guide to the tropical shallow water genera of the Central-West Pacific, the Indian Ocean and the Red Sea. Australian Institute of Marine Science, Townsville

Fabricius KE, Dommisse M (2000) Depletion of suspended particulate matter over coastal reef communities dominated by zooxanthellate soft corals. Mar Ecol Prog Ser 196: $157-167$

> Grottoli AG, Rodrigues LJ, Juarez C (2004) Lipids and stable carbon isotopes in two species of Hawaiian corals, Porites compressa and Montipora verrucosa, following a bleaching event. Mar Biol 145:621-631

Harland AD, Navarro JC, Davies PS, Fixter LM (1993) Lipids of some Caribbean and Red Sea corals-total lipid, wax esters, triglycerides and fatty acids. Mar Biol 117:113-117

Imbs AB, Dautova TN (2008) Use of lipids for chemotaxonomy of octocorals (Cnidaria: Alcyonaria). Russ J Mar Biol 34: $174-178$

Imbs AB, Demina OA, Demidkova DA (2006) Lipid class and fatty acid composition of the boreal soft coral Gersemia rubiformis. Lipids 41:721-725

Imbs AB, Demidkova DA, Latypov YY, Pham QL (2007a) Application of fatty acids for chemotaxonomy of reefbuilding corals. Lipids 42:1035-1046

> Imbs AB, Latyshev NA, Zhukova NV, Dautova TN (2007b) Comparison of fatty acid compositions of azooxanthellate Dendronephthya and zooxanthellate soft coral species. Comp Biochem Physiol B 148:314-321 
Imbs AB, Luu HV, Pham LQ (2007c) Intra- and interspecific variability of fatty acid composition of the soft corals. Russ J Mar Biol 33:67-70

Imbs AB, Demidkova DA, Dautova TN, Latyshev NA (2009) Fatty acid biomarkers of symbionts and unusual inhibition of tetracosapolyenoic acid biosynthesis in corals (Octocorallia). Lipids 44:325-335

Imbs AB, Yakovleva IM, Pham LQ (2010) Distribution of lipids and fatty acids in the zooxanthellae and host of the soft coral Sinularia sp. Fish. Sci. 76:375-380

Joseph JD (1979) Lipid composition of marine and estuarine invertebrates: Porifera and Cnidaria. Prog Lipid Res 18:1-30

Kaneda T (1991) Iso-fatty and anteiso-fatty acids in bacteriabiosynthesis, function, and taxonomic significance. Microbiol Rev 55:288-302

Lam CN, Nguen HK, Stekhov VB, Svetashev VI (1981) Phospholipids and fatty acids of soft corals. Russ J Mar Biol 6:44-47

Latyshev NA, Nguen HK, Do NT, Svetashev VI (1986) Composition and seasonal variations of phospholipids content of alcyonarians. Russ J Mar Biol 3:52-56

Latyshev NA, Naumenko NV, Svetashev VI, Latypov YY (1991) Fatty acids of reef building corals. Mar Ecol Prog Ser 76:295-301

Meyers PA (1977) Fatty acids and hydrocarbons of Caribbean corals. Proc 3rd Int Coral Reef Symp 1:529-536

Meyers PA (1979) Polyunsaturated fatty acids in coral: indicators of nutritional sources. Mar Biol Lett 1:69-75

Oku H, Yamashiro H, Onaga K, Sakai K, Iwasaki H (2003) Seasonal changes in the content and composition of lipids in the coral Goniastrea aspera. Coral Reefs 22:83-85

Papina M, Meziane T, van Woesik R (2003) Symbiotic zooxanthellae provide the host-coral Montipora digitata with polyunsaturated fatty acids. Comp Biochem Physiol B 135: 533-537

Patton JS, Burris JE (1983) Lipid synthesis and extrusion by freshly isolated zooxanthellae (symbiotic algae). Mar Biol 75:131-136

Patton JS, Battery JF, Rigler MW, Porter JW, Black CC, Burris JE (1983) A comparison of metabolism of bicarbonate ${ }^{14} \mathrm{C}$ and acetate $1-{ }^{14} \mathrm{C}$ and the variability of species lipid components in reef corals. Mar Biol 75:121-130

Pham QL, Luu VH, Imbs AB, Dautova TN (2008) Lipid and fatty acids of Vietnamese coral reefs - biochemical diversity. Science and Technology Publishing House, Hanoi

Rodrigues LJ, Grottoli AG, Pease TK (2008) Lipid class composition of bleached and recovering Porites compressa Dana, 1846 and Montipora capitata Dana, 1846 corals from Hawaii. J Exp Mar Biol Ecol 358:136-143
Saunders SM, Radford B, Bourke SA, Thiele Z, Bech T, Mardon J (2005) A rapid method for determining lipid fraction ratios of stony corals under varying sediment and light regimes. Environ Chem 2:331-336

Sorokin YI (1993) Coral reef ecology. Springer, Heidelberg

Stimson JS (1987) Location, quantity and rate of change in quantity of lipids in tissue of Hawaiian hermatypic corals. Bull Mar Sci 41:889-904

Svetashev VI, Vysotsky MV (1998) Fatty acids of Heliopora coerulea and chemotaxonomic significance of tetracosapolyenoic acids in coelenterates. Comp Biochem Physiol B 119:73-75

Tchernov D, Gorbunov MY, de Vargas C, Yadav SN, Milligan AJ, Haggblom M, Falkowski PG (2004) Membrane lipids of symbiotic algae are diagnostic of sensitivity to thermal bleaching in corals. Proc Natl Acad Sci USA 101: 13531-13535

Treignier C, Grover R, Ferrier-Pages C, Tolosa I (2008) Effect of light and feeding on the fatty acid and sterol composition of zooxanthellae and host tissue isolated from the scleractinian coral Turbinaria reniformis. Limnol Oceanogr 53:2702-2710

van Oppen MJH, Mieog JC, Sanchez CA, Fabricius KE (2005) Diversity of algal endosymbionts (zooxanthellae) in octocorals: the roles of geography and host relationships. Mol Ecol 14:2403-2417

> Viso AC, Marty JC (1993) Fatty acids from 28 marine microalgae. Phytochemistry 34:1521-1533

- Volkman JK (1999) Australian research on marine natural products: chemistry, bioactivity and ecology. Mar Freshw Res 50:761-779

- Ward S (1995) Two patterns of energy allocation for growth, reproduction and lipid storage in the scleractinian coral Pocillopora damicornis. Coral Reefs 14:87-90

Wells JW (1956) Scleractinia. In: Moore RC (ed) Treatise on invertebrates. Paleontology Coelenterata. University of Kansas Press, Lawrence, p 328-440

> Yamashiro H, Oku H, Higa H, Chinen I, Sakai K (1999) Composition of lipids, fatty acids and sterols in Okinawan corals. Comp Biochem Physiol B 122:397-407

> Yamashiro H, Oku H, Onaga K, Iwasaki H, Takara K (2001) Coral tumors store reduced level of lipids. J Exp Mar Biol Ecol 265:171-179

Yamashiro H, Oku H, Onaga K (2005) Effect of bleaching on lipid content and composition of Okinawan corals. Fish Sci 71:448-453

Zhukova NV, Titlyanov EA (2003) Fatty acid variations in symbiotic dinoflagellates from Okinawan corals. Phytochemistry 62:191-195

Submitted: August 18, 2009; Accepted: April 14, 2010

Proofs received from author(s): June 17, 2010
Editorial responsibility: Brian Helmuth,

Columbia, South Carolina, USA 